\title{
TEORIA SOCIAL E O RACISMO NO BRASIL
}

DOIS ATLÂNTICOS: TEORIA SOCIAL, ANTI-RACISMO, COSMOPOLITISMO,

de Sérgio Costa. Belo Horizonte: Editora UFMG, 2006.

JOSUÉ PEREIRA DA SILVA

Sérgio Costa inicia seu livro afirmando que ele "nasceu do interesse intelectual e político de melhor compreender as discussões contemporâneas em torno do combate ao racismo no Brasil" (p. 11). Para alcançar tal objetivo, ele recorre à metáfora dos dois Atlânticos Atlântico Norte e Atlântico Negro - , para articular o que se poderia chamar de dois programas de pesquisa: um de natureza teórica geral (no sentido de grande teoria), que trata do cosmopolitismo; e outro que, embora seja também teórico, é mais específico de abrangência, pois trata de um caso empírico, i. e., o problema do racismo no Brasil. Ambos estão distribuídos ao longo dos sete capítulos que compõem o livro: os três primeiros dedicam-se à discussão de três abordagens do cosmopolitismo contemporâneo e os últimos três lidam com o problema do racismo no Brasil. O capítulo quatro, intermediário, funciona como ponte entre as duas ordens temáticas; nele, o autor procura estabelecer mediações entre os contextos nacionais e transnacionais a partir da categoria "contextos transnacionais de ação".

O primeiro capítulo do livro é dedicado à discussão da concepção habermasiana do cosmopolitismo. Depois de um esforço bemsucedido para vincular a obra mais teórica de Habermas com seu diagnóstico de época, Costa concentra sua crítica nas inconsistências que vê na tentativa de transpor uma teoria elaborada tendo em vista um contexto nacional ou quando muito regional para o contexto pós-nacional de um mundo globalizado. Ou seja, nas palavras de Costa, "o projeto de Habermas para promover a integração social e política pós-nacional consiste, fundamentalmente, em buscar 'equivalentes funcionais' para aqueles elementos-chave em sua teoria - nacional - da democracia" (p.25). Para Costa, um tal empreendimento exigiria uma teoria social pós-nacional, a qual, 
segundo ele, Habermas não dispõe. Por isso, a transposição de uma teoria nacional para um contexto global contém inconsistências que afetam a própria concepção de uma democracia cosmopolita, tal como postulada pelo autor alemão.

Uma teoria social adequada às condições de um mundo globalizado demanda, portanto, uma epistemologia cosmopolita. Costa trata do problema no segundo capítulo do livro, a partir da análise das teorias de Ulrich Beck e de Anthony Giddens, em cujas concepções de cosmopolitismo os conceitos de risco e de reflexividade ocupam lugar de destaque. Beck e Giddens são sociólogos com trajetórias intelectuais diferentes. Beck tem um trabalho de natureza mais ensaística e se tornou conhecido mundialmente por seu livro de 1986 sobre a sociedade de risco. Giddens, por sua vez, consolidou sua fama como um teórico social no sentido mais estrito, em especial pela formulação do que denominou "teoria da estruturação", um esforço de síntese que pretende unir,em uma só teoria, as abordagens originárias do estruturalismo e da sociologia da ação. Costa está alerta para essa diferença entre os dois autores, mas chama a atenção para a aproximação entre os diagnósticos de época e as preocupações temáticas nos trabalhos mais recentes de ambos.Assim, a noção de modernização reflexiva emerge como um unificador na concepção dos dois autores a respeito do cosmopolitismo e da globalização. Apesar da ambição de ambos em formular alternativas teóricas que levem em conta esse contexto globalizado, a concepção que elaboram a respeito da globalização não está isenta, segundo Costa, de equívocos semelhantes àqueles que estavam presente na teoria da modernização do imediato pós-Segunda Guerra: "globalização seria, assim, o processo que leva, com algum atraso de tempo, a alta modernidade do Atlântico Norte para o resto do mundo" (p.74).

Talvez as abordagens pós-coloniais, analisadas no terceiro capítulo, ofereçam saídas mais satisfatórias para os dilemas atuais da teoria social. Embora não se trate de uma única matriz teórica, os chamados estudos pós-coloniais têm como objetivo comum "a 'desconstrução’ da polaridade West/Rest” (i. e., o Ocidente e o resto). Estão em questão, aqui, em especial a hegemonia do chamado Atlântico Norte e a pretensão de universalidade dos discursos ali elaborados, porque, para os autores pós-coloniais, esses discursos hegemônicos falam de algum lugar que está longe de ser universal. Esta contestação, que não é externa aos discursos do Atlântico Norte e em grande medida se inspiram neles, põe em questão a suposta superioridade tanto desses discursos como das culturas e das sociedades das quais tais discursos emergem. A crítica aos binarismos e às antinomias objetiva a relativização do lugar privilegiado ocupado pelos discursos hegemônicos e, ao mesmo tempo, questiona as hierarquias entre as culturas e as epistemologias dominantes. 
A crítica empreendida pelos autores pós-coloniais à polaridade "West/Rest" tem como alvo, portanto, o viés colonialista presente na própria produção de conhecimento, uma vez que a tendência do discurso hegemônico é construir e legitimar uma assimetria irreversível entre o Ocidente e os outros, i.e., constrói uma superioridade não apenas circunstancial e histórica, mas ontológica eessencializada. Para os autores pós-coloniais, essa polaridade é inócua do ponto de vista cognitivo, pois, em vez de elucidar, ofusca os fenômenos que pretende elucidar. Por um lado, as formulações pós-coloniais têm seus méritos, do ponto de vista cognitivo, ao possibilitar uma percepção mais balanceada da modernidade global, através de conceitos como modernidades múltiplas ou modernidades entrelaçadas; por outro, elas padecem de déficits no plano normativo, em parte por se tratar de um conjunto heterogêneo de formulações distintas, e, em parte, por seu caráter ensaístico. Ou seja, são bem-sucedidas na desconstrução analítica mas pecam por carecer de uma reconstrução normativa convincente. Isso fica evidente nos dois autores discutidos no quarto capítulo (Stuart Hall e Paul Gilroy), cujas contribuições são consideradas por Costa as mais fecundas para o desenvolvimento de uma sociologia transnacional, adequada para o estabelecimento de nexos entre os macrodiagnósticos daépoca atual (pressupostos nas diversas concepções de cosmopolitismo) eo problema do racismo no Brasil. Nenhum dos dois autores pós-coloniais mencionados acima define, por exemplo, um lugar prévio para a emancipação social, como fazem outras abordagens, como o marxismo com o proletariado, a teoria crítica de Habermas com o conceito de razão comunicativa ou de Axel Honneth com o conceito de reconhecimento. Para Costa, então, nem a "política de representações" de Hall nem o "Attântico Negro" de Gilroy consegue ser satisfatório do ponto de vista normativo.

A metáfora dos dois Atlânticos constitui-se, entretanto, em uma importante chave para desmontar o paradoxo entre a idéia de que "o racismo corresponde à suposição de uma hierarquia qualitativa entre os seres humanos" (p. 11) e a ambição do cosmopolitismo de expressar um universalismo abstrato que fecha os olhos para os efeitos socioeconômicos e culturais do racismo, cujo imaginário contribuiu para criar. Transposta para a teoria social, essa hierarquia qualitativa entre seres humanos transparece também em uma hierarquia entre as sociedades e suas respectivas culturas, com as sociedades do Atlântico Norte ocupando o topo da hierarquia. É esse o sentido da expressão "West and the Rest", utilizada por Stuart Hall, em que "West" referese às sociedades do Atlântico Norte e as outras são "the Rest". Esse tipo de pressuposto hierárquico entre as sociedades é, segundo Costa, um componente das teorias da modernização, para as quais as socie- 
dades do Atlântico Norte representariam o ponto máximo de progresso econômico, social e cultural, que deveria ser buscado pelas demais sociedades. A metáfora do Atlântico Negro é por isso mesmo uma crítica direta às teorias da modernização. Isso explica também por que, para o livro aqui resenhado, o "ponto de partida é o estudo crítico de tentativas de recuperar o conceito 'cosmopolitismo'” (p.13).

Evidentemente, Costa não descarta o cosmopolitismo tout court. Apesar de seus limites, o cosmopolitismo contemporâneo serve como um corretivo epistemológico às teorias sociológicas do pós-Segunda Guerra que tinham no Estado-nação a unidade analítica privilegiada, unidade analítica que o autor considera insatisfatória no atual contexto do mundo globalizado. Um dos objetivos do livro é, portanto, construir mediações que permitam uma melhor intelecção do vínculo entre as dimensões globais (cosmopolitismo) e locais (manifestação cotidiana do racismo). Daí, o debate brasileiro sobre o anti-racismo ser um dos pontos focais da análise.

Depois de uma apropriação crítica das três abordagens anteriores, Sérgio Costa passa, nos três últimos capítulos, à discussão do problema mais empírico do livro, queé racismo no Brasil.Partindo de uma reconstrução do debate histórico e sociológico em uma larga escala temporal, que vai do século XIX até o presente, Costa discute o racismo científico e sua recepção no Brasil, o movimento negro em seus diferentes momentos, assim como a relação entre a sociologia norte-americana (mais especificamente a dos Estados Unidos) eo racismo no Brasil. Em sua análise, Costa contrapõe as abordagens e visões sobre esses diferentes problemas, chamando a atenção para as contribuições, mas realçando ao mesmo tempo os limites ou carências de cada uma delas. No final, fica claro seu esforço em buscar uma alternativa que evite os riscos de essencialização típica dos chamados estudos raciais, mas que ao mesmo tempo não se contente com as proposições generalizantes e abstratas que tendem a ignorar os efeitos sociais e culturais do racismo na vida cotidiana. O que Sérgio Costa busca é, portanto, um ponto de equilíbrio fundado no que considera as supostas virtudes dos estudos raciais (a demanda por políticas que combatam efetivamente o racismo), assim como nas dos chamados críticos dos estudos raciais (a preocupação com o risco de essencialização contido em políticas baseadas na noção de raça). Não é uma tarefa fácil, masé um objetivo que vale o esforço; sua plausibilidade, no entanto, não depende apenas dos debates acadêmicos como alguns discutidos nesse livro. Por se tratar de um processo em curso, ela depende também, e sobretudo, da ação dos movimentos sociais e das políticas públicas na área.

Por fim, se considerarmos o objetivo maior do livro, queé investigar as "possibilidades de tradução e mediação entre a política anti-racista 
desenvolvida transnacionalmente e sua implementação" (p. 219) no Brasil, pode-se considerar que o empreendimento foi bem-sucedido, pois seu autor conseguiu, através da análise sistemática de uma bibliografia rica e diversificada, estabelecer claras conexões entre o debate sobre o racismo no Brasil e mais amplamente no âmbito do Atlântico Negro (Hall, Gilroy), e as formulações teóricas de autores como Habermas, Giddens e Beck, com suas concepções de cosmopolitismo. Mais do que isso:Sérgio Costa o conseguiu com um acurado senso crítico em relação a todos esses autores, fazendo-o, porém, com a necessária empatia que permite uma leitura não preconceituosa de cada um deles. Por tudo isso, o livro constitui-se em uma importante contribuição que ajuda a avançar a reflexão tanto sobre o problema do racismo, como sobre a teoria social de maneira geral.

JosuÉ PEREIRA DA SilVAé professor de Sociologia na Unicamp. 